\title{
ZEXNEP KAMIL MEDICAL JOURNAL
}

Formerly Zeynep Kamil Tıp Bülteni

111 Qbstetrics and Gynecology 112 Rediatrics and Pediatric Surgery 



\title{
EDITORIAL BOARD
}

\author{
EDITOR-IN-CHIEF \\ Semra KAYATAŞ ESER, MD \\ University of Health Sciences, İstanbul, Turkey
}

\author{
EDITORS \\ Ayşenur CELAYIR, MD \\ University of Health Sciences, İstanbul, Turkey \\ PInar KUMRU, MD \\ University of Health Sciences, İstanbul, Turkey
}

Rabia Gönül SEZER YAMANEL, MD

University of Health Sciences, İstanbul, Turkey

\begin{abstract}
SECTION EDITORS
Murat API, MD Güner KARATEKIN, MD

Gynecological Oncology, Neonatology,

University of Health Sciences, İstanbul, Turkey University of Health Sciences, İstanbul, Turkey

Oya DEMiRCi, MD Nilüfer ELDEŞ HACIFAZLIOĞLU, MD

Perinatology, Pediatric Neurology,

University of Health Sciences, İstanbul, Turkey University of Health Sciences, İstanbul, Turkey

Ebru ÇÖGENDEZ, MD Mustafa ÇAKAN, MD

Reproductive Endocrinology, Pediatric Rheumatology,

University of Health Sciences, İstanbul, Turkey University of Health Sciences, İstanbul, Turkey
\end{abstract}

\section{PUBLISHER}

Kare Publishing

Address: Dumlupınar Mah., Cihan Sok., No: 15, Concord İstanbul, B Blok 162, Kadıköy, İstanbul, Turkey

Phone: +90 2165506111

Fax: +902165506112

E-mail: kare@karepb.com

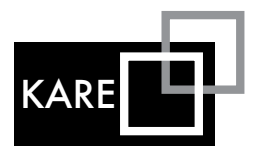


PUBLISHING MANAGER

PInar KUMRU, MD

University of Health Sciences, İstanbul,

Turkey

\author{
Alberto PENA, MD \\ Ali KUCUKMETIN, MD \\ United Kingdom \\ Aspazija SOFIJANOVA, MD \\ North Macedonia \\ Aytan Kamal MAMMADBAYLI, MD
}

Azerbaijan
ENGLISH EDITING

Ayşe Selma DAĞTAŞ

\section{INTERNATIONAL ADVISORY BOARD}

\author{
Camila KURBANOVA, MD \\ Azerbaijan \\ Dilorom I. AKHMEDOVA, MD \\ Uzbekistan \\ Emre SELI, MD \\ United States of America \\ Fahrija SKOKIC, MD \\ Bosnia and Herzegovina
}

\section{BIOSTATISTICS}

\section{PInar KUMRU, MD}

University of Health Sciences, İstanbul, Turkey

\section{EDITORIAL BOARD / ADVISORY BOARD}

Abdullah YILDIZ, MD

University of Health Sciences, İstanbul,

Turkey

Abdülkadir BOZAYKUT, MD

University of Health Sciences, İstanbul,

Turkey

Ahmet ESER, MD

University of Health Sciences, İstanbul,

Turkey

Ahmet Zeki IŞIK, MD

Ali insan DOKUCU, MD

University of Health Sciences, İstanbul,

Turkey

Ali KARAMAN, MD

University of Health Sciences, İstanbul,

Turkey

Arzu ŞENCAN, MD

Health Sciences University, İzmir, Turkey
Ayșe KARAMAN, MD

Ankara City Hospital, Ankara, Turkey

Ayşenur CELAYiR, MD

University of Health Sciences, İstanbul, Turkey

Aytekin KAYMAKÇI, MD

University of Health Sciences, İstanbul, Turkey

Baha ORAL, MD

Süleyman Demirel University, Isparta, Turkey

Barış ATA, MD

Koç University, İstanbul, Turkey

Belgin DEVRANOĞLU, MD

University of Health Sciences, İstanbul, Turkey

Bülent Taner KARADAĞ, MD

Marmara University, İstanbul, Turkey
Jorge CARRILLO, MD

United States of America

Juan Diego VILLEGAS, MD

Colombia

Kubilay ERTAN, MD

Germany

Sagynbu ABDUVALIEVA, MD

Kyrgyzstan

\section{Canan KABACA KOCAKUŞAK, MD}

University of Health Sciences, İstanbul, Turkey

Cem FIÇICIOĞLU, MD

Acıbadem University, İstanbul, Turkey

Cem DemireL, MD

Memorial Hospital, İstanbul, Turkey

Cenk BÜYÜKÜNAL, MD

İstanbul University-Cerrahpaşa,

Cerrahpaşa Faculty of Medicine, İstanbul,

Turkey

Çetin Ali KARADAĞ, MD

University of Health Sciences, İstanbul,

Turkey

Çetin KILIÇCI, MD

University of Health Sciences, İstanbul, Turkey 
Çiğdem YAYLA ABiDE, MD

University of Health Sciences, İstanbul,

Turkey

Derya BÜYÜKAYHAN, MD

University of Health Sciences, İstanbul, Turkey

Ebru ÇÖĞENDEZ, MD

University of Health Sciences, İstanbul,

Turkey

Ecmel KAYGUSUZ, MD

University of Health Sciences, İstanbul,

Turkey

Elif ÖZALKAYA, MD

University of Health Sciences, İstanbul,

Turkey

Elif Yüksel KARATOPRAK, MD

Medeniyet University, İstanbul, Turkey

Enis ÖZKAYA, MD

University of Health Sciences, İstanbul,

Turkey

Erbil ÇAKAR, MD

University of Health Sciences, İstanbul, Turkey

Erdal SARI, MD

University of Health Sciences, İstanbul,

Turkey

Erkut ATTAR, MD

Yeditepe University, İstanbul, Turkey

Esra ESIM BÜYÜKBAYRAK, MD

Marmara University, İstanbul, Turkey

Evrim BOSTANCI ERGEN, MD

University of Health Sciences, İstanbul,

Turkey

Fahri OVALI, MD

Medeniyet University, İstanbul, Turkey

Fuat DEMIRCi, MD

Güner KARATEKIN, MD

University of Health Sciences, İstanbul,

Turkey

Gürkan BOZDAĞ, MD

Hacettepe University, Ankara, Turkey

Handan ÇETINER, MD

University of Health Sciences, İstanbul,

Turkey

IIhan ŞANVERDi, MD

University of Health Sciences, İstanbul, Turkey
Ilke ÖZAHI, MD

Medipol University, İstanbul, Turkey

Levent ELEMEN, MD

University of Health Sciences, İstanbul, Turkey

Mahmut DOĞRU, MD

Mehmet ELiÇEVIK, MD

İstanbul University-Cerrahpaşa,

Cerrahpaşa Faculty of Medicine, İstanbul,

Turkey

Melih AKIN, MD

University of Health Sciences, İstanbul, Turkey

Murat API, MD

University of Health Sciences, İstanbul, Turkey

Mustafa ÇAKAN, MD

Pediatric Rheumatology, University of

Health Sciences, İstanbul, Turkey

Mustafa EROĞLU, MD

University of Health Sciences, İstanbul, Turkey

Münevver HOŞGÖR, MD

Health Sciences University, İzmir, Turkey

Müşerref Banu YILMAZ, MD

University of Health Sciences, İstanbul, Turkey

Nazmiye Nilgün KARADAĞ, MD

University of Health Sciences, İstanbul, Turkey

Nilüfer ELDEŞ HACIFAZLIOĞLU, MD

Pediatric Neurology, University of Health

Sciences, İstanbul, Turkey

Olcay ÜNVER, MD

Marmara University, İstanbul, Turkey

Orkan ERGÜN, MD

Ege University Faculty of Medicine, İzmir,

Turkey

Oya DEMiRCi, MD

University of Health Sciences, İstanbul, Turkey

Pinar KUMRU, MD

University of Health Sciences, İstanbul, Turkey
Rabia GÖNÜL SEZER YAMANEL, MD

University of Health Sciences, İstanbul, Turkey

Recep HAS, MD

İstanbul University, İstanbul, Turkey

Sadık ŞAHIN, MD

University of Health Sciences, İstanbul,

Turkey

Selçuk AYAS, MD

Okan University İstanbul, Turkey

Selçuk ÖZDEN, MD

Sakarya University, Sakarya Turkey

Selim SANCAK, MD

University of Health Sciences, İstanbul,

Turkey

Semra KAYATAŞ ESER, MD

University of Health Sciences, İstanbul,

Turkey

Serdar MORALIOĞLU, MD

University of Health Sciences, İstanbul,

Turkey

Sevilay TOPÇUOĞLU, MD

University of Health Sciences, İstanbul,

Turkey

Sinan CELAYIR, MD

İstanbul University-Cerrahpaşa,

Cerrahpaşa Faculty of Medicine, İstanbul,

Turkey

Şirin GÜVEN, MD

University of Health Sciences, İstanbul,

Turkey

Taner YAVUZ, MD

Okan University, İstanbul, Turkey

Tuğrul TiRYAKi, MD

Ankara City Hospital, Ankara, Turkey

Tülay GÜRAN, MD

Marmara University, İstanbul, Turkey

Volkan Sarper ERiKçi, MD

Health Sciences University, İzmir, Turkey

Yakup KUMTEPE, MD

Atatürk University, Erzurum, Turkey

Zekeriya ILÇE, MD

University of Health Sciences, İstanbul,

Turkey 


\section{INFORMATION FOR THE AUTHORS}

The Zeynep Kamil Medical Journal is an international, scientific, open access periodical published in accordance with independent, unbiased, and double-blinded peer-review principles. The journal is the official publication of the Zeynep Kamil Women and Children Diseases Training and Research Hospital, and it is published in March, June, September and December, four times a year. The publication language of the journal is English.

The Zeynep Kamil Medical Journal aims to contribute to international literature by publishing high-quality manuscripts in the field of Obstetrics and Gynecology, Pediatrics and Pediatric Surgery. The journal's target audience includes academics and expert physicians working in Obstetrics and Gynecology, Pediatrics and Pediatric Surgery specialists.

\section{REVIEW PROCESS}

Manuscripts submitted to the Zeynep Kamil Medical Journal will undergo a double-blind peer-review process. Each submission will be reviewed by at least two external, independent peer reviewers who are experts in their field in order to ensure an unbiased evaluation process. The editorial board will invite an external and independent editor to manage the evaluation process of manuscripts submitted by editors or by the editorial board members of the journal. The editor-in-chief is the final authority in the decision-making process for all submissions.

Reviews are typically completed within one month of submission to the journal. Authors will be sent constructive reviewer comments intended to be useful. In general, the instructions, objections, and requests made by the reviewers should be followed. The revised manuscript should clearly and precisely indicate every step taken in accordance with the reviewers' notes. A list of responses and the corrections made to each comment should be provided.

\section{AUTHORSHIP}

Each individual listed as an author should fulfill the authorship criteria recommended by the International Committee of Medical Journal Editors (ICMJE - www.icmje.org). The ICMJE recommends that authorship be based on the following 4 criteria:

Substantial contributions to the conception or design of the work, or the acquisition, analysis, or interpretation of data for the work; AND

Drafting the work or revising it critically for important intellectual content; AND

Final approval of the version to be published; AND

Agreement to be accountable for all aspects of the work in ensuring that questions related to the accuracy or integrity of any part of the work are appropriately investigated and resolved.

In addition to being accountable for their own work, authors should have confidence in the integrity of the contributions of their co-authors and each author should be able to identify which co-authors are responsible for other parts of the work.
All of those designated as authors should meet all four criteria for authorship, and all who meet the four criteria should be identified as authors. Those who do not meet all four criteria should be acknowledged on the title page of the manuscript.

The Zeynep Kamil Medical Journal requires that corresponding authors submit a signed and scanned version of the authorship contribution form (available for download through https://www.zeynepkamilmedj.com/) during the initial submission process in order to appropriately indicate and observe authorship rights and to prevent ghost or honorary authorship. If the editorial board suspects a case of "gift authorship," the submission will be rejected without further review. As part of the submission of the manuscript, the corresponding author should also send a short statement declaring that they accept all responsibility for authorship during the submission and review stages of the manuscript.

\section{ORCID ID}

The Open Researcher and Contributor ID (ORCID) number of each author must be submitted when creating an account for correspondence. To obtain an ORCID number, please visit https://orcid.org/

\section{PLAGIARISM DETECTION}

All submissions are screened using similarity detection software at least two times: on submission and after completing revisions. In the event of alleged or suspected research misconduct, e.g., plagiarism, citation manipulation, or data falsification/fabrication, the editorial board will follow and act in accordance with COPE guidelines. Plagiarism, including self-plagiarism, that is detected at any stage will result in rejection of the manuscript.

\section{Publication Charges}

This journal assesses no submission fees, publication fees, or page charges.

\section{MANUSCRIPT PREPARATION}

Manuscripts should be prepared in accordance with the ICMJERecommendations for the Conduct, Reporting, Editing, and Publication of Scholarly Work in Medical Journals (updated in December 2015 http://www.icmje.org/icmje-recommendations.pdf). Authors are required to prepare manuscripts in accordance with the Consolidated Standards of Reporting Trials (CONSORT) guidelines for randomized research studies, the STrengthening the Reporting of OBservational studies in Epidemiology (STROBE) guidelines for observational original research studies, the Standards for Reporting Diagnostic Accuracy (STARD) guidelines, the Preferred Reporting Items for Systematic Reviews and Meta-Analyses (PRISMA) guidelines, the Animal Research: Reporting of In Vivo Experiments (ARRIVE) guidelines for experimental animal studies, and the Transparent Reporting of Evaluations with Nonrandomised Designs (TREND) guidelines for non-randomized behavioral and public health evaluations. 
Manuscripts may only be submitted through the journal's online manuscript submission and evaluation system, http://jag.journalagent. com/zkmj/ Manuscripts submitted via any other medium will not be evaluated.

Manuscripts will first be submitted to a technical evaluation process in which the editorial staff will ensure that the manuscript has been prepared and submitted in accordance with the journal's guidelines. Submissions that do not conform to the journal's guidelines will be returned to the author with requests for technical correction.

The quality and clarity of the language used in a manuscript is very important. The editors may request that authors have the manuscript professionally edited if the language of the submission does not conform to the journal standards. The Zeynep Kamil Medical Journal uses American English. Please submit text of a quality ready for publication. Information about language editing and copyediting services pre- and post-submission may contact Kare Publishing at kare@karepb.com. Please refer to specific formatting requirements noted in the submission checklist and elsewhere in this document.

\section{MANUSCRIPT TYPES}

Original Article: This is the most valued type of article, since it provides new information based on original research. The main text of an original article should be structured with Introduction, Methods, Results, Discussion, and Conclusion subheadings. Original articles are limited to 3500 words and 30 references.

Review Article: Two kinds of review are accepted for publication in the Zeynep Kamil Medical Journal: narrative review and systematic review. Reviews of relevant topics not recently discussed in this format that will be helpful to readers are welcomed.

Case Report: There is limited space for case reports and therefore the journal selects reports of rare cases or conditions that reflect challenges in diagnosis and treatment, those offering new therapies or revealing knowledge not in the literature, or present something otherwise particularly interesting and educative. The abstract with structured of background, case and conclusion, is limited to 150 words and the report must include the subheadings of introduction, case report, and discussion, which includes a conclusion. A case report is limited to 1300 words and 15 references.
Image: Original, high-quality clinical or laboratory images will be considered for publication. If a photo of an identifiable patient is used, a consent form for its use must be completed and signed by the patient and enclosed with the submission. All printed information that might identify the patient or the authors' institution (including, but not limited to the hospital or patient name, date, or place) should be removed from images. The submission should have no more than 3 authors, the case description is limited to a maximum of 200 words, the discussion section may contain no more than 200 words, and only 3 references and 3 figures are permitted.

Letter to the Editor: This type of manuscript discusses important observations, overlooked aspects, or details lacking in a previously published article. Noteworthy articles on subjects within the scope of the journal, particularly educative cases, may also be submitted in the form of a "Letter to the editor." No abstract, keywords, tables, figures, images, or other media should be included. The article that is the subject of commentary must be properly cited within the manuscript. The text should be unstructured and is limited to 500 words. No more than 5 references will be accepted (Table 1).

Cover Letter: The cover letter should include the article title, article type, and the full name of the corresponding author and a statement declaring the absence or presence of any conflict of interest. The corresponding author should briefly summarize the paper and affirm that it has not already been published, accepted, or is under simultaneous review for publication elsewhere. It should be stated that if the manuscript is accepted by the Zeynep Kamil Medical Journal, the paper will not be published elsewhere in the same form, in English or in any other language.

Title Page: A separate title page should be submitted with all submissions and this page should include:

- The full title of the manuscript as well as a short title (running head) of no more than 50 characters

- Name, affiliation, ORCID ID number, and highest academic degree of the author(s)

- Funding and other material support

- Name, address, phone number(s), fax number, and email address of the corresponding author

- Acknowledgment of the individuals who contributed to the preparation

Table 1: Limitations for each manuscript type

\begin{tabular}{|c|c|c|c|c|c|}
\hline Type of manuscript & Word limit & Abstract word limit & Reference limit & Table limit & Figure limit \\
\hline Original Article & 3500 & 350 (Structured) & 40 & 6 & 6 \\
\hline Case Report & 1500 & 200 & 15 & No tables & 5 \\
\hline Letter to the Editor & 1000 & No abstract & 10 & No tables & No media \\
\hline
\end{tabular}


of the manuscript but who do not fulfill the authorship criteria

- Manuscripts that have been presented orally or as a poster should include the name, date and place of the event

Abstract: An English-language abstract is required with all submissions except editorial comments, images, and letters to the editor. Systematic reviews and original articles should contain a structured abstract of maximum 250 words with the subheadings of objective, methods, results, and conclusion.

Keywords: Each submission must be accompanied by a minimum of three and a maximum of six keywords for subject indexing included at the end of the abstract. The keywords should be listed in full without abbreviations. The keywords should be selected from the National Library of Medicine, Medical Subject Headings database (https://www. nlm.nih.gov/mesh/MBrowser.html).

Tables: Tables should be uploaded as separate files and not embedded in the main text. They should be numbered consecutively in the order they are referred to within the main text. A descriptive title must be placed above the tables. Abbreviations used in the tables should be defined below the table with footnotes, even if they are defined within the main text. Tables should be created using the "insert table" command of the word processing software and they should be designed for easy reading. Data presented in tables should not be a repetition of the data presented within the main text but should support the main text.

Figures and Figure Legends: Figures, graphics, and photographs should be submitted as separate files in TIFF or JPEG format through the article submission system. The files should not be embedded in a Word document or the main document. When there are figure subunits, the subunits should not be merged to form a single image. Each subunit should be submitted separately through the submission system. Images should not be labeled (a, b, c, etc.) to indicate figure subunits. Thick and thin arrows, arrowheads, stars, asterisks, and similar marks can be used on the images to support figure legend. Like the rest of the submission, the figures should be blind. Any information within the images that may identify an individual or institution should be blinded. The minimum resolution of each submitted figure should be 300 DPI. To prevent delays in the evaluation process, all submitted figures should be clear in resolution and large in size (minimum dimensions: $100 \times 100 \mathrm{~mm}$ ). Figure legends should be listed at the end of the main document.

All acronyms and abbreviations used in the manuscript should be defined at first use, both in the abstract and in the main text. The abbreviation should be provided in parentheses following the definition. Units should be prepared in accordance with the International System of Units (SI). When a drug, device, hardware, or software program, or other product is mentioned within the main text, the name of the product, the manufacturer/copyright holder of the product (not simply the vendor), and city and the country of the company (including the state, if in USA), should be provided in parentheses in the following format: "Discovery St PET/CT scanner (General Electric Co., Boston, MA, USA)".
All references, tables, and figures should be referred to within the main text, and they should be numbered consecutively in the order they are referred to within the main text.

Limitations, drawbacks, and shortcomings of original articles should be mentioned in the Discussion section before the conclusion paragraph.

References: The editorial team may request that the authors cite related recently published articles (preferably within the last 10 years) in their manuscripts, with the exception of historical papers.

If an ahead-of-print publication is cited, the digital object identifier (DOI) number should be provided. Authors are responsible for the accuracy of references. Journal titles should be abbreviated in accordance with the journal abbreviations in the Index Medicus /MEDLINE/ PubMed. When there are six or fewer authors, all authors should be listed. If there are seven or more authors, the first six should be listed followed by "et al." In the main text of the manuscript, references should be cited using Arabic numerals in parentheses. The reference styles for different types of publications are presented in the following examples.

Journal article: van Erk MD, Dam-Vervloet AJ, de Boer FA, Boomsma MF, van Straaten $\mathrm{H}$, Bosschaart $\mathrm{N}$. How skin anatomy influences transcutaneous bilirubin determinations: an in vitro evaluation. Pediatr Res 2019;86:471-7.

Epub ahead-of-print article: Cai L, Yeh BM, Westphalen AC, Roberts JP, Wang ZJ. Adult living donor liver imaging. Diagn Interv Radiol 2016 Feb 24. doi: 10.5152/dir.2016.15323. [Epub ahead-of-print].

Manuscript published in electronic format: Morse SS. Factors in the emergence of infectious diseases. Emerg Infect Dis (serial online) 1995 Jan-Mar (cited 1996 June 5): 1(1): (24 screens). Available from: URL: http:/ www.cdc.gov/ncidodIEID/cid.htm.

Book section: Suh KN, Keystone JS. Malaria and babesiosis. Gorbach SL, Barlett JG, Blacklow NR, editors. Infectious Diseases. Philadelphia: Lippincott Williams; 2004.p.2290-308.

Books with a single author: Sweetman SC. Martindale the Complete Drug Reference. 34 ${ }^{\text {th }}$ ed. London: Pharmaceutical Press; 2005.

Editor(s) as author: Huizing $\mathrm{EH}$, de Groot JAM, editors. Functional reconstructive nasal surgery. Stuttgart-New York: Thieme; 2003.

Conference proceedings: Bengisson S. Sothemin BG. Enforcement of data protection, privacy and security in medical informatics. In: Lun KC, Degoulet P, Piemme TE, Rienhoff O, editors. MEDINFO 92. Proceedings of the $7^{\text {th }}$ World Congress on Medical Informatics; 1992 Sept 6-10; Geneva, Switzerland. Amsterdam: North-Holland; 1992. pp.1561-5.

Scientific or technical report: Cusick M, Chew EY, Hoogwerf B, Agrón E, Wu L, Lindley A, et al. Early Treatment Diabetic Retinopathy Study Research Group. Risk factors for renal replacement therapy in the Early Treatment Diabetic Retinopathy Study (ETDRS), Early Treatment Diabetic Retinopathy Study Kidney Int: 2004. Report No: 26. 


\section{REVISIONS}

When submitting a revised version of a paper (include a clean copy and a highlighted copy), the author must submit a detailed response to the reviewers that replies to each issue raised by the reviewers and indicates where changes can be found (each reviewer's comment, followed by the author's reply and line number where changes have been made) as well as an annotated copy of the main document. Revised manuscripts must be submitted within 30 days from the date of the decision letter. If the revised version of the manuscript is not submitted within the allocated time, the revision option may be withdrawn. If the submitting author(s) believe that additional time is required, they should request this extension within the initial 30-day period.

Accepted manuscripts are copy edited for grammar, punctuation, format, and clarity. Once the publication process of a manuscript is completed, it is published online on the journal's webpage as an ahead-of-print publication before it is included in the scheduled issue. A PDF proof of the manuscript is sent to the corresponding author and their publication approval is requested within 2 days of receipt of the proof.

\section{PUBLICATION PROCESS}

Accepted manuscripts will be made available and citable online as rapidly as possible. The stages of publication are as follows;

Uncorrected publication: A PDF of the final, accepted (but unedited and uncorrected) paper will be published online on the journal web page under the "Accepted Articles" section. A DOI will be assigned to the article at this stage.

Ahead-of-print publication: After copy editing, typesetting, and review of the resulting proof, the final corrected version will be added online in the "Ahead-of-Print" section.

Final publication: The final corrected version will appear in an issue of the journal and added to the journal website. To ensure rapid publication, we ask authors to provide your publication approval during the proofreading process as quickly as possible, and return corrections within 48 hours of receiving the proof.

\section{SUBMISSION CHECKLIST}

Please use this list and the following explanations to prepare your manuscript and perform a final check before submission to ensure a timely review.

\section{Formatting of text}

- Text should be written in 12-point Times New Roman font

- Main headings and subheadings should be in 12-point and bold font

- Type a single space at the end of each sentence

- Do not use bold face for emphasis within the text

- Numbers one to ten are written out in words unless they are used as a unit of measurement, except in figures and tables

- Use a single hard return to separate paragraphs. Do not use tabs or indents to start a paragraph

- Do not use software options for hyphenation, headers, or footers

- Use page numbering
- Use line numbers

- Use US English

\section{Ensure that the following items are present:}

Cover letter

Title page including:

- Article type

- Article title

- Running title

- All author names and affiliations

- One author has been designated as the corresponding author with contact details

- Full postal address, phone number(s), and email address

- Acknowledge

- Manuscripts that have been presented orally or as a poster must include the name of the event, the date, and the location

- State financial or other support for the study

- Word count

${ }^{\circ}$ Abstract word count

- Text word count

Main text of the manuscript must include:

- Article title

- Abstract

- Keywords

- Text with required subheadings

- References (ensure written according to journal rules)

- Figures and tables

- Numbered according to text citation

- Descriptive legends/titles and abbreviations

- Ensure all figure and table citations in the text match the files provided

- Figures: to be submitted separately.

- Tables: to be submitted separately

Ensure that the following forms have been properly completed and submitted:

- ICMJE Potential Conflict of Interest Disclosure Form (completed by all contributing authors), AND

- Copyright Transfer Form, AND

- Author Contributions Form

These forms are available for download at www.zeynepkamilmedj.com.

\section{Further review}

- Check the statistical analysis

- Use the US English spell check and grammar check software functions

- Check that all references cited in the text are correctly listed in the reference list

- Permission has been obtained for use of copyrighted material from other sources (including the Internet)

- All abbreviations have been identified

- All figures and tables are correctly labeled

- Journal policies detailed in this guide have been followed. 


\section{CONTENTS}

\section{ORIGINAL ARTICLES}

Serum endocan concentration in women with placenta accreta.

Yayla Abide Ç, Yenidede İ, Kılıççı Ç, Bostancı E, Eser A, Dağ I, Tosun Ö, Özkaya E

Evaluation of gestational trophoblastic diseases; 10 years' experience in tertiary obstetric care center

Kale i, Topal CS

Negative pressure wound therapy in gynecological oncology

Yüksel D, Alınca CM, Kılıç Ç, Çakır C, Turan T, Kimyon Cömert G, Koç S, Boran N, Kayıkçıoğlu F

Comparison of outcomes of frozen-thawed transfer of day 5 blastocysts and day 6 blastocysts

Tülek F, Kahraman A

Evaluation of the relationship between ocular surface symptoms and platelet-to-lymphocyte ratio in COVID-19 patients

Önal Günay B, Kalkışım A, Esenülkü CM, Çelik G

Foreign body in esophagus of children with previous esophageal surgery history

Ayvaz OD, Celayir A, Erdeve B

A major diagnostic criterion for acute rheumatic fever: Clinical and sub-clinical carditis accompaniment with Sydenham chorea

Erol N, Özen M, Bozaykut A

\section{CASE REPORTS}

Profilactic usage of $\mathrm{N}$-acetyl cysteine in the treatment of tuberculosis in children may be effective in protection from hepatotoxicity: A case experience 202-205

Yetmiş E, Bayrak NA, Nuhoğlu Ç

Anaphylaxis that develops following application of egg white on an area of burn 206-208

Emeksiz ZŞ, Özmen S

$52^{\text {TH }}$ VOLUME INDEX

Reviewer List 